\title{
TU/e EmonONEN

\section{Limits to performance spread tuning using adaptive voltage and body biasing}

\section{Citation for published version (APA):}

Meijer, M., Pessolano, F., \& Pineda de Gyvez, J. (2005). Limits to performance spread tuning using adaptive voltage and body biasing. In IEEE International Symposium on Circuits and Systems (ISCAS 2005), 23 - 26 May 2005, Kobe, Japan (Vol. 1, pp. 5-8). Institute of Electrical and Electronics Engineers. https://doi.org/10.1109/ISCAS.2005.1464510

DOI:

10.1109/ISCAS.2005.1464510

Document status and date:

Published: 01/01/2005

\section{Document Version:}

Publisher's PDF, also known as Version of Record (includes final page, issue and volume numbers)

\section{Please check the document version of this publication:}

- A submitted manuscript is the version of the article upon submission and before peer-review. There can be important differences between the submitted version and the official published version of record. People interested in the research are advised to contact the author for the final version of the publication, or visit the $\mathrm{DOI}$ to the publisher's website.

- The final author version and the galley proof are versions of the publication after peer review.

- The final published version features the final layout of the paper including the volume, issue and page numbers.

Link to publication

\section{General rights}

Copyright and moral rights for the publications made accessible in the public portal are retained by the authors and/or other copyright owners and it is a condition of accessing publications that users recognise and abide by the legal requirements associated with these rights.

- Users may download and print one copy of any publication from the public portal for the purpose of private study or research.

- You may not further distribute the material or use it for any profit-making activity or commercial gain

- You may freely distribute the URL identifying the publication in the public portal.

If the publication is distributed under the terms of Article 25fa of the Dutch Copyright Act, indicated by the "Taverne" license above, please follow below link for the End User Agreement:

www.tue.nl/taverne

Take down policy

If you believe that this document breaches copyright please contact us at:

openaccess@tue.nl

providing details and we will investigate your claim. 


\title{
Limits to Performance Spread Tuning using Adaptive Voltage and Body Biasing
}

\author{
Maurice Meijer*, Francesco Pessolano^, and José Pineda de Gyvez* \\ *Philips Research Laboratories \\ ^Philips Semiconductors \\ Eindhoven, The Netherlands
}

\begin{abstract}
In this paper we examine technology constraints on tuning active power and delay using adaptive voltage scaling (AVS) and adaptive body biasing (ABB) design techniques. To serve this purpose, a test circuit was fabricated in a $90 \mathrm{~nm}$ triple-well low-power CMOS technology. The analysis hereby presented is based on a ring oscillator running at $488 \mathrm{MHz}$ and a circular shift register with $8 \mathrm{~K}$ flip-flops and $50 \mathrm{~K}$ gates. Measurement results indicate that it is possible to reach $\mathbf{2 4 . 4 x}$ power savings by $6.1 x$ frequency downscaling using AVS, $\pm \mathbf{2 4 \%}$ power and $\pm \mathbf{2 2 \%}$ frequency tuning at nominal conditions using ABB only, 127x power savings with $37.4 x$ frequency downscaling by combining AVS and ABB.
\end{abstract}

\section{INTRODUCTION}

Manufacturing variations of fundamental design parameters and the search for optimum low-power designs have opened avenues to the application of adaptive techniques to control the power supply $\left(\mathrm{V}_{\mathrm{DD}}\right)$ and threshold voltage $\left(\mathrm{V}_{\text {th }}\right)$. Design technologies such as AMD's PowerNow! [1], Transmeta's LongRun [2], Intel's Enhanced SpeedStep [3] are vivid examples of commercial ICs that use power management based on power supply scaling. In addition, chip demonstrators with $V_{D D}$ and $V_{\text {th }}$ scaling capabilities have also been reported in the literature archival [4]-[8]. Other reported uses of $\mathrm{V}_{\mathrm{DD}}$ and $\mathrm{V}_{\text {th }}$ scaling, besides power management in processors, are in testing [9], product binning [10], and yield tuning [11].

In this paper we investigate technology constraints on active-power and delay tuning. In particular we are interested in finding what power-delay tradeoffs can be made, how $\mathrm{V}_{\mathrm{DD}}$ and $\mathrm{V}_{\text {th }}$ scaling relate to circuit activity and investigate how far can process-dependent performance spread be tuned.

Our test chip consists of a clock generator unit (CGU) and a circular shift register in a triple-well low-power (LP) $90 \mathrm{~nm}$ CMOS technology with a nominal power supply of $1.2 \mathrm{~V}$. The CGU consists of seven independent ringoscillators and corresponding selection circuitry. The ringoscillators use minimum sized inverters as delay elements, a 2-input NAND gate for enabling control, and a divide-by-2 circuit for duty cycle recovery. The shift register contains $8 \mathrm{~K}$ flip-flops and 50K logic gates. The logic gates are connected as delay lines between two consecutive flip-flops, which have an average logic depth of 6 . One can emulate the activity of a core with this circular shift register by shifting in a sequence of zeros and ones. The design was laid out with a commercial place-and-route tool using constrained arearouting features for both circuit blocks. The circuit has independent bias control over its PMOS and NMOS transistors by properly adjusting the N-well and P-well voltages, respectively. Measurements were performed using an Agilent 93K SoC test system in a controlled temperature (25degC) environment enabled by a Temptronic thermostream. The fastest measured oscillator runs at a frequency of $488 \mathrm{MHz}$. In the remainder of this paper, we will refer to the ring oscillator as "ringo".

In [13] we have already shown the results for the CGU when fabricated in a general-purpose (GP) $90 \mathrm{~nm}$ CMOS technology with a nominal supply of $1 \mathrm{~V}$. The results shown in this paper extend the results in [13] in two ways: (i) we will show results for a power-optimized $90 \mathrm{~nm}$ CMOS technology, and (ii) we will report $\mathrm{V}_{\mathrm{DD}}$ and $\mathrm{V}_{\text {th }}$ scaling ranges to tune process-dependent performance spreads.

Section 2 introduces the voltage conventions we used for AVS and ABB. In section 3 we will focus on frequency scaling as well as frequency tuning. Section 4 deals with the use of AVS and $\mathrm{ABB}$ for reduction of power demand. Section 5 explores the potential of AVS and ABB for online performance compensation.

\section{SCALING OPERATIONS}

We will now briefly describe the adaptive voltage scaling (AVS) and adaptive body bias (ABB) schemes. An AVS operation consists in sweeping the power supply while maintaining the body bias constant. $\mathrm{ABB}$ is essentially the contrary approach: $\mathrm{V}_{\mathrm{DD}}$ is kept constant and the body bias is swept. Finally, AVS+ABB is the case when both body biasing and power supply are swept. Table 1 presents the voltage ranges we have employed during our measurements. Observe that the wells were forward biased for at most $0.6 \mathrm{~V}$ and reverse biased by $1.2 \mathrm{~V}$, independently of the power supply value. Forward biasing is constrained by the turn-on 
voltage of the transistors' body-to-source junction diode. Essentially, reverse biasing is unconstrained, but high reverse biasing voltages result in increased (junction) leakage. We will now illustrate how these techniques can be used to alter the performance of integrated circuits.

TABLE I. VOLTAGE CONVENTIONS FOR SCALING OPERATIONS

\begin{tabular}{|c|c|c|c|}
\hline Operation & Description & Variable & Range \\
\hline AVS & $\begin{array}{l}\text { Adaptive } \\
\text { Voltage Scaling }\end{array}$ & $V_{D D}$ & {$[0.6,1.2] \mathrm{V}$} \\
\hline ABB & $\begin{array}{l}\text { Adaptive Body } \\
\text { Biasing }\end{array}$ & $\begin{array}{l}V_{\text {nwell }} \\
V_{\text {pwell }}\end{array}$ & $\begin{array}{l}{\left[\mathrm{V}_{\mathrm{DD}}-0.6, \mathrm{~V}_{\mathrm{DD}}+1.2\right] \mathrm{V}} \\
{[-1.2,0.6] \mathrm{V}}\end{array}$ \\
\hline AVS+ABB & $\begin{array}{l}\text { Adaptive } \\
\text { Voltage and } \\
\text { Body Biasing }\end{array}$ & $\begin{array}{l}V_{D D} \\
V_{n w e l l} \\
V_{p w e l l}\end{array}$ & $\begin{array}{l}{[0.6,1.2] \mathrm{V}} \\
{\left[\mathrm{V}_{\mathrm{DD}}-0.6, \mathrm{~V}_{\mathrm{DD}}+1.2\right] \mathrm{V}} \\
{[-1.2,0.6] \mathrm{V}}\end{array}$ \\
\hline
\end{tabular}

\section{FREQUENCY SCALING AND TUNING}

Let us first investigate the dynamic range of the ring oscillator. To a first order approximation the frequency can be calculated as $f \approx \mathrm{K} \cdot \mathrm{V}_{\mathrm{DD}}{ }^{-1}\left(\mathrm{~V}_{\mathrm{DD}}-\mathrm{V}_{\mathrm{th}}\right)^{\alpha}$ [12], where $f$ is the frequency of operation, $K$ is a proportionality factor and $\alpha$ is a process dependent parameter that models velocity saturation. In the case of velocity-saturated devices, $\alpha$ is close to 1 . Because of the low $\alpha$ factor, it follows then that frequency scales almost linearly with $\mathrm{V}_{\mathrm{DD}}$.

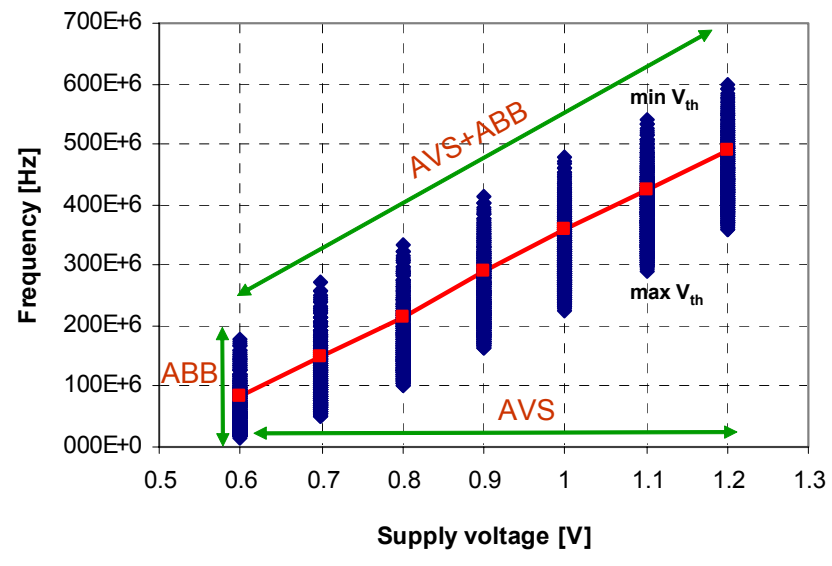

Figure 1. Frequency scaling and tuning for the ringo.

Figure 1 shows the ringo frequency as function of power supply. Each cloud of dots is associated to a unique $\mathrm{V}_{\mathrm{DD}}$ value. Each dot in a cloud corresponds to a unique $\mathrm{N}$-well and P-well bias combination, and the line joining clouds indicates the nominal trend. Observe that the frequency increases by $6.1 \mathrm{x}$ when $\mathrm{V}_{\mathrm{DD}}$ is scaled up from $0.6 \mathrm{~V}$ to $1.2 \mathrm{~V}$.

We can now analyze the impact of $\mathrm{ABB}$ as a frequency tuning mechanism at each $\mathrm{V}_{\mathrm{DD}}$ point. Notice from Figure 1 that the relative tuning range is not the same for all $\mathrm{V}_{\mathrm{DD}}$ values. In particular, we measured frequency spans of approximately $\pm 80 \%$ at $\mathrm{V}_{\mathrm{DD}}=0.6 \mathrm{~V}$ and $\pm 22 \%$ at $\mathrm{V}_{\mathrm{DD}}=1.2 \mathrm{~V}$ w.r.t. their nominal frequencies. This unbalance is because the effective gate drive of the transistors is smaller at low $\mathrm{V}_{\mathrm{DD}}$ values. For the measured silicon, $\mathrm{ABB}$ gives an absolute tuning range of $241 \mathrm{MHz}$ for the chosen well voltages operating at a nominal power supply of $1.2 \mathrm{~V}$.

\section{POWER AND FREQUENCY TUNING}

The ultimate goal of the AVS and ABB schemes is performance tuning with performance being the optimal combination of frequency and power, i.e. the lowest power for a fixed frequency. Figure 2 presents a plot of frequency as function of the total power of the CGU, e.g. both CGUstatic and dynamic power consumption of the ringo.

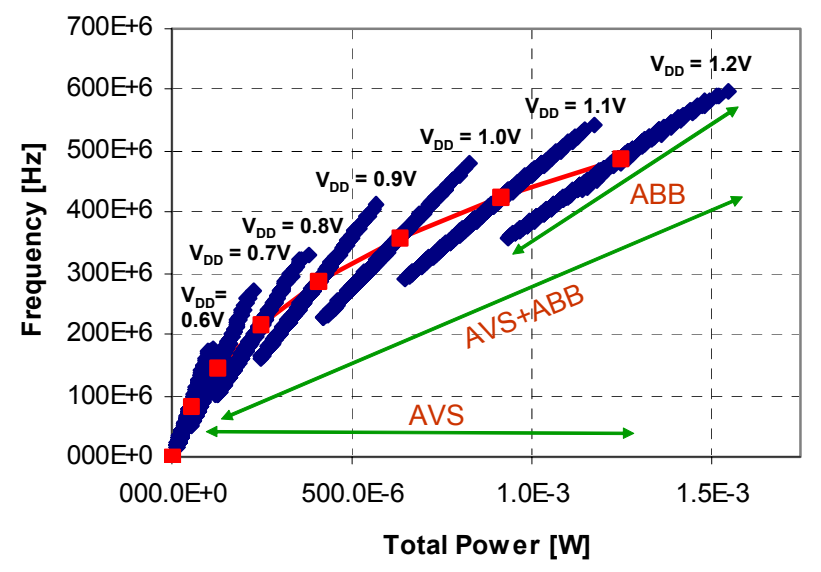

Figure 2. Frequency versus total power.

The plot of Figure 2 puts us in state to evaluate power savings and tuning range control of AVS and ABB. Measurement results of the ringo indicate a $24.4 \mathrm{x}$ power savings by $6.1 \mathrm{x}$ frequency downscaling using AVS over half of the entire $\mathrm{V}_{\mathrm{DD}}$ range. The use of $\mathrm{ABB}$ at $\mathrm{V}_{\mathrm{DD}}=1.2 \mathrm{~V}$ results in $\pm 24 \%$ power and $\pm 22 \%$ frequency tuning w.r.t the nominal operating point. The combination of AVS and ABB yields $127 \mathrm{x}$ power savings with $37.4 \mathrm{x}$ frequency scaling from the highest possible frequency (minimum $\mathrm{V}_{\text {th }}$ ) to the lowest one (maximum $\mathrm{V}_{\text {th }}$ ). These results show the strength of the combined use of AVS and ABB.

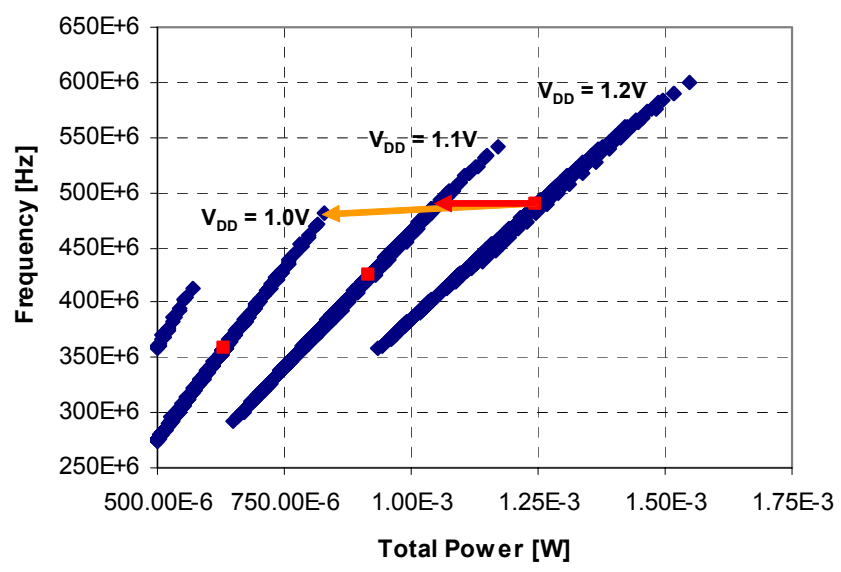

Figure 3. Frequency versus total power trade-off. 
Let us now explore possible performance tradeoffs by using AVS and ABB. Figure 3 shows a zoom-in of Figure 2 at $\mathrm{V}_{\mathrm{DD}}=1.2 \mathrm{~V}$. If AVS and $\mathrm{ABB}$ are applied such that the nominal $\mathrm{V}_{\mathrm{DD}}$ becomes $1.1 \mathrm{~V}$ instead of $1.2 \mathrm{~V}$, and the $\mathrm{V}_{\text {th }}$ 's are pulled to a smaller value as indicated by the arrow in Figure 3, we see that it is possible to achieve $16 \%$ power savings w.r.t. the nominal conditions at no frequency penalty. A more aggressive $\mathrm{V}_{\mathrm{DD}}$ downscaling to $1.0 \mathrm{~V}$, while pulling the $\mathrm{V}_{\text {th }}$ 's to their minimum value, results in 33\% power savings at less than $1 \%$ frequency penalty. It is clear, thus, that AVS $+\mathrm{ABB}$ can lead to significant power savings without serious performance penalty.

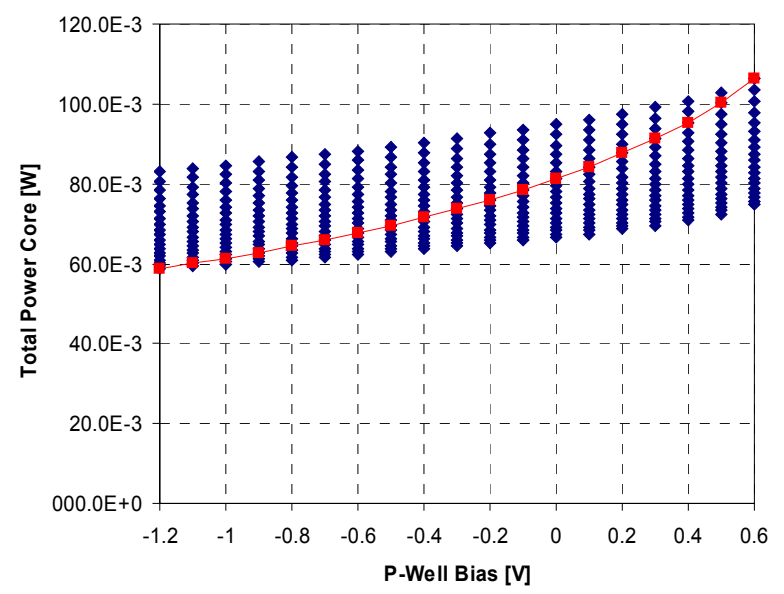

Figure 4. Total power of the core as a function of well biasing.

Next we investigate the properties of ABB on the shift register. Figure 4 shows the core's total power for a given circuit activity, $\mathrm{V}_{\mathrm{DD}}=1.2 \mathrm{~V}$ and scaling of the P-well biasing; each dot in the clouds is associated to the N-well biasing. The line joining clouds indicates the case when symmetric well biasing is applied. Observe that the well biasing allows a total power tuning range of about $50 \mathrm{~mW}$; this represents half of the nominal power consumption.

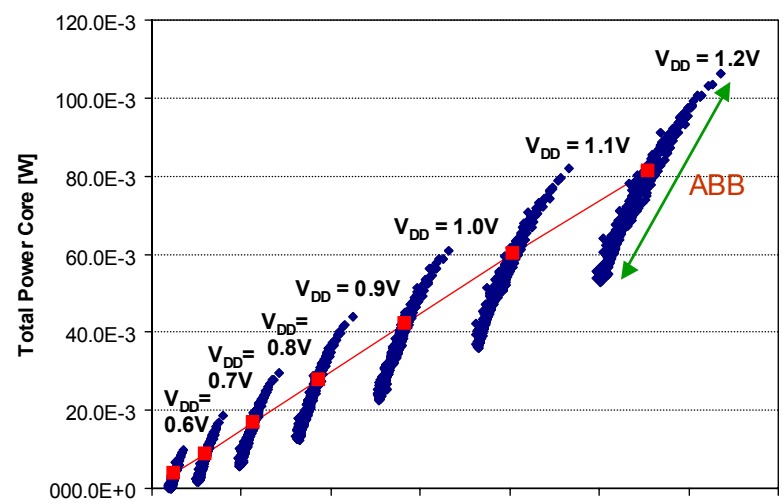

200.0E-6 400.0E-6 600.0E-6 800.0E-6 $\quad 1.0 \mathrm{E}-3 \quad 1.2 \mathrm{E}-3 \quad 1.4 \mathrm{E}-3$

Total Power Ringo [W]

Figure 5. Total power correlation for the shiftregister and the ringo for different $\mathrm{V}_{\mathrm{DD}}$ values.
Figure 5 shows a power correlation between the shift register and the ringo for different $\mathrm{V}_{\mathrm{DD}}$ values. In this plot we have used the same conventions as before, i.e. each cloud is associated to a unique $\mathrm{V}_{\mathrm{DD}}$ value and each point in the cloud corresponds to a unique $\mathrm{N}$-well and $\mathrm{P}$-well bias combination. The shift register operates at the same $\mathrm{V}_{\mathrm{DD}}$ as the ringo, while its operating frequency is provided by the ringo. The circuit activity of the shift register is kept constant. The dynamic power dominates the total power in both circuit blocks, and therefore, their total power consumption can be estimated by $P \approx \mathrm{aC} \cdot \mathrm{V}_{\mathrm{DD}}{ }^{2} \cdot f$, where $\mathrm{aC}$ represents the switching circuit capacitance, $\mathrm{V}_{\mathrm{DD}}$ is the power supply voltage and $f$ is the frequency of operation. Since both circuit blocks operate at the same $\mathrm{V}_{\mathrm{DD}}$ and $f$, their power consumption is linearly related by a ratio determined by the switching circuit capacitance. This can be observed in Figure 5 , where the power consumption of the circuit blocks remains linearly correlated while applying AVS and/or ABB.

\section{PERFORMANCE COMPENSATION}

As the variation of fundamental parameters such as channel length, threshold voltage, thin oxide thickness and interconnect dimensions goes well beyond acceptable limits, "on the fly" performance compensation is becoming necessary. While process spreads are tightly controlled, their impact on circuit design and behavior is higher and higher. For instance, while before a $V_{\text {th }}$ variation of say $50 \mathrm{mV}$ on a nominal $\mathrm{V}_{\text {th }}$ of $450 \mathrm{mV}$ was not that crucial, in deep submicron technologies with a nominal $\mathrm{V}_{\text {th }}$ of $250 \mathrm{mV}$ this variation can make circuit operation quite difficult.

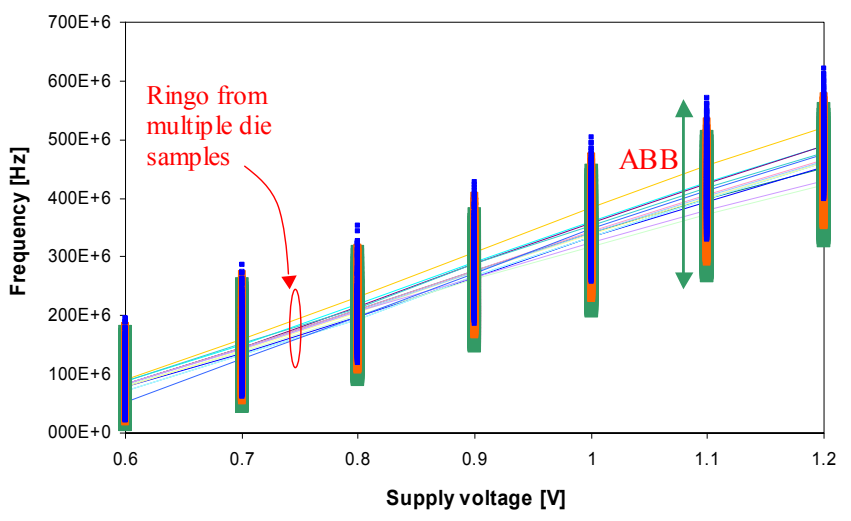

Figure 6. Frequency spread and performance tuning.

Figure 6 shows an example of performance spread in which frequency is plotted against power supply for twelve different samples. Additionally, frequency tuning using ABB for three selected samples is shown as well. Samples were selected as "fast", "typical" and "slow" with nominal frequencies of $521 \mathrm{MHz}, 477 \mathrm{MHz}$, and $453 \mathrm{MHz}$, respectively. The total frequency spread of the limited sample set of the ringo is $68 \mathrm{MHz}$. Despite this spread, it is possible to tune its frequency to the "typical" ringo. This gives basically a $100 \%$ parametric yield improvement. 
Let us investigate now up to what extent the frequency spread can be compensated. When ABB is used while operating at the nominal supply voltage, the frequency range of the "fast" ringo is $399 \mathrm{MHz}<f_{\text {fast }}<629 \mathrm{MHz}$, the one of the "slow" ringo is $329 \mathrm{MHZ}<f_{\text {slow }}<558 \mathrm{MHz}$, while the "typical" ringo operates in the range of $354 \mathrm{MHz}<f_{\text {typical }}<$ $581 \mathrm{MHz}$. Notice that the tuning is continuous for all frequencies.

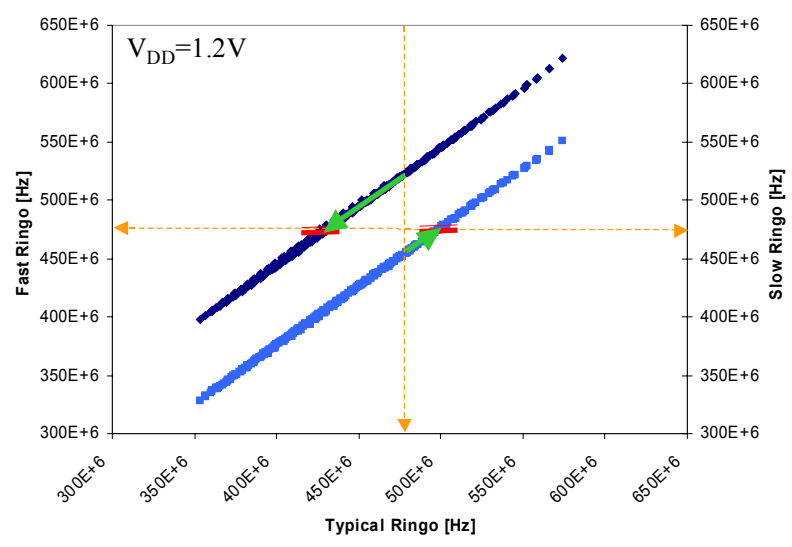

Figure 7. "Fast" to "typical" ringo and "slow" to "typical" ringo performance compensation.

Figure 7 shows a frequency correlation between sample "fast", sample "slow" and sample "typical". As an example we use $\mathrm{ABB}$ to lower the nominal frequency of the "fast" sample to the one of the "typical" sample as indicated by arrow A. Several combinations of $\mathrm{V}_{\text {th }}$ 's can provide the required frequency of $477 \mathrm{MHz}$. For our limited sample set, performance compensation could be achieved using a symmetric bias for $\mathrm{N}$-well and $\mathrm{P}$-well of value $300 \mathrm{mV}$ reverse and $200 \mathrm{mV}$ forward bias.

\section{CONCLUSIONS}

We presented measurement results that show the extent to which adaptive voltage scaling and adaptive body bias are useful for active-power and delay tuning in a state-of-the-art CMOS technology. Although the results were obtained from this particular $90 \mathrm{~nm}$ CMOS technology, they are well suited as indices for reference purposes.

This paper shows that AVS renders a wide frequencyscaling control and significant power savings. The index factors are $24.4 \mathrm{x}$ power savings by $6.1 \mathrm{x}$ frequency downscaling. While the frequency and power tuning range of ABB may look limited (index factors $\pm 24 \%$ power and $\pm 22 \%$ frequency tuning @ $\mathrm{V}_{\mathrm{DD}}=1.2 \mathrm{~V}$ ), the frequency tuning range proves to be effective for process-dependent performance compensation. In fact, we observed a continuous frequency tuning despite the wide frequency spread. With AVS and ABB together it is possible to attain $127 \mathrm{x}$ power savings with $37.4 \mathrm{x}$ frequency downscaling. These indices show that the combined use of AVS and ABB offers significant performance control.
More work is needed to qualify this design technology in deep sub micrometer technologies, e.g. to assess the implications of $\mathrm{V}_{\mathrm{DD}}$ and $\mathrm{V}_{\text {th }}$ scaling on circuit activity, noise margins, power supply noise among other parameters.

\section{ACKNOWLEDGMENT}

We would like to thank Rutger van Veen, Bram Kruseman, Dick Heslinga, and Atul Katoch who helped us through various phases of this investigation.

\section{REFERENCES}

[1] AMD PowerNOW! Technology, AMD white paper, November 2000, http://www.amd.com

[2] M. Fleishman, "Longrun power management; Dynamic power management for Crusoe processor", Transmeta white paper, January 2001, http://www.transmeta.com

[3] S. Gochman., R. Ronen, I. Anati, A. Berkovits, T. Kurts, A. Naveh, A. Saeed, Z. Sperber and R. Valentine, "The Intel Pentium M processors: microarchitecture and performance", Intel Technology Journal, May 2003, Vol.7, Issue 2, p. 22-36

[4] T. Kuroda, K. Suzuki, S. Mita, T. Fujita, F. Yamane, F. Sano, A. Chiba, Y. Watanabe, K. Matsuda, T. Maeda, T. Sakurai and T. Furuyama, "Variable supply-voltage scheme for low-power highspeed CMOS digital design", IEEE Journal of Solid-State Circuits, March 1998, Vol.33, No.3, p. 454-462

[5] K. Nowka, G. Carpenter, E. MacDonald, H. Ngo, B. Brock, K. Ishii, T. Nguyen and J. Burns, "A 32-bit PowerPC system-on-a-chip with support for dynamic voltage scaling and dynamic frequency scaling", IEEE Journal of Solid-State Circuits, November 2002, Vol.37, No.11, p. 1441-1447

[6] V. Gutnik and A. Chandrakasan, "Embedded power supply for lowpower DSP", IEEE Transactions on Very Large Scale Integration (VLSI) Systems, December 1997, Vol.5, No.4, p.425-435

[7] G. Wei and M. Horowitz, "A fully digital, energy-efficient adaptive power-supply regulator", IEEE Journal of Solid-State Circuits, April 1999, Vol.34, No.4, p. $520-528$

[8] N. Dragone, A. Aggarwal and L. Carley, "An adaptive on-chip voltage regulation technique for low-power applications", Proc. of International Symposium on Low Power Electronic Design, July 2000, p. 20-24

[9] T. Miyake, T. Yamashita, N. Asari, H. Sekisaka, T. Sakai, K. Matsuura, A. Wakahara, H. Takahashi, T. Hiyama, K. Miyamoto, and K. Mori, "Design Methodology of High Performance Microprocessor using Ultra-Low Threshold Voltage CMOS", Proc. of IEEE Custom Integrated Circuits Conference, 2001, p. 275-278

[10] J. Tschanz, J. Kao, S. Narendra, R. Nair, D. Antoniadis, A. Chandrakasan, and Vivek De, "Adaptive body bias for reducing impacts of die-to-die and within-die parameter variations on microprocessor frequency and leakage", IEEE Solid-State Circuits Conference, February 2002, Vol.1, p. 422-478

[11] T. Chen and S. Naffziger, "Comparison of Adaptive Body Bias (ABB) and Adaptive Supply Voltage (ASV) for Improving Delay and Leakage Under the Presence of Process Variation", IEEE Transactions on VLSI Systems, October 2003, Vol. 11, No. 5, p. 888-899

[12] T. Sakurai and R. Newton, "Alpha-Power Law MOSFET Model and its Applications to CMOS Inverter Delay and Other Formulas", IEEE Journal of Solid-State Circuits, April 1990, Vol.25, No.2, p. 584-593

[13] M. Meijer, F. Pessolano and J. Pineda de Gyvez, "Technology Exploration for Adaptive Power and Frequency Scaling in 90nm CMOS", Proc. of International Symposium on Low Power Electronic Design, August 2004, p.14-19 